\title{
Study of Dust Mites in Three Birmingham Hospitals
}

\author{
M. E. BLYTHE, F. AL UBAYDI, J. D. WILLIAMS, J. MORRISON SMITH
}

British Medical fournal, 1975, 1, 62-64

\section{Summary}

Samples of dust were collected from wards in a general hospital, a geriatric hospital, and a skin hospital. Mites were found on the floors of all three hospitals; Surprisingly, the skin hospital showed fewer mites than the general hospital. The differences were attributed to the variation in ward activity, the number of visitors on the wards, and the differing cleaning regimens.

Plastic-covered mattresses were almost completely free from mites, but foci were found on soft furnishings and on the jackets and overcoats of hospital workers.

The total numbers of mites were small compared to those found in house dust, and hospital mites probably do not constitute a serious problem for asthmatic patients.

\section{Introduction}

Children suffering from asthmatic attacks often show a rapid improvement on admission to hospital. The reasons for this improvement are not obvious, and while the psychological effects of reassurance must be considered it is pertinent to inquire whether there are important allergens in the home environment from which the patients are protected while in hospital.

One of the most important and ubiquitous of the common allergens is the house-dust allergen, thought to be produced by and present in the bodies and faeces of mites of the family Pyroglyphidae (Acarina) which abound in house dust (Spieksma, 1967; Voorhorst et al., 1969), particularly the dust of domestic mattresses (Cunnington, 1967; Blythe et al., 1974). We therefore carried out studies on the prevalence of these mites in hospital wards.

\section{Methods}

The floors, beds, and furnishings of the medical and paediatric wards of a district general hospital, the wards of a geriatric hospital next to it, and the wards of a small skin hospital one and a half miles $(2.4 \mathrm{~km})$ away were examined. Dust samples were taken from the hospital floors with a small portable vacuum cleaner with a disposable paper bag attached in place of the normal bag. After sampling the bag was removed and the vacuum cleaner was run for half a minute without a bag and shaken to dislodge any dust remaining inside.

A parallel series of samples was collected by brushing dust

\footnotetext{
Department of Microbiology, Dudley Road Hospital, Birmingham 18

M. E. BLYTHE, B.sC., Research Fellow

F. AL UBAYDI, M.B., M.SC., Research Fellow

J. D. WILLIAMS, M.D., M.R.C.PATH., Consultant Microbiologist (Present address: The London Hospital Medical College, London E1 2AD)

Department of Chest Diseases, Dudley Road Hospital and Birmingham Chest Clinic

J. MORRISON SMITH, M.D., F.R.C.P., Consultant Physician
}

directly into the paper bag with a small brush to check on the reliability of the vacuum method.

Each dust sample was weighed, suspended in $90 \%$ lactic acid in a glass Petri dish, and warmed on a hotplate for 24 hours. The mites were removed under a $\times 10$ stereo microscope.

The vacuum cleaner was also used to collect dust samples from hospital mattresses and soft furnishings and from street clothes and jackets of hospital workers.

\section{Results}

The results of the samples taken from different parts of the district general hospital are shown in table I. Pyroglyphidae were regularly present on the ward floors, being found in 23 out of $50(46 \%)$ of the vacuum-cleaner samples and 16 out of 40 $(40 \%)$ of the brushed samples, but the densities were low-3.9 pyroglyphid mites per $100 \mathrm{mg}$ for the vacuum-cleaner samples. Pyroglyphidae made up $80.8 \%$ of the mites found in the vacuum-cleaner samples.

TABLE I-Distribution of Mites in Various Areas Sampled in the General Hospital

\begin{tabular}{|c|c|c|c|c|c|c|}
\hline & & $\begin{array}{l}\text { No. of } \\
\text { Samples }\end{array}$ & $\begin{array}{l}\text { No. of } \\
\text { Samples } \\
\text { Positive } \\
\text { for } \\
\text { Mites } \dagger\end{array}$ & $\begin{array}{c}\text { Amount } \\
\text { of } \\
\text { Dust } \\
\text { (mg) }\end{array}$ & $\begin{array}{l}\text { Total } \\
\text { No. of } \\
\text { Mites } \dagger\end{array}$ & $\begin{array}{l}\text { Mites/ } \\
100 \mathrm{mg} \dagger\end{array}$ \\
\hline 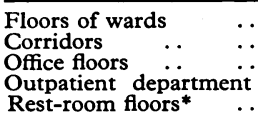 & $\begin{array}{l}\ldots \\
\cdots \\
\cdots \\
\cdots\end{array}$ & $\begin{array}{r}50 \\
14 \\
4 \\
8 \\
12\end{array}$ & $\begin{aligned} 23 & (27) \\
6 & (11) \\
1 & (2) \\
4 & (4) \\
2 & (6)\end{aligned}$ & $\begin{array}{r}1522.7 \\
673.4 \\
140.0 \\
548.8 \\
309.9\end{array}$ & $\begin{array}{r}59(73) \\
14(23) \\
2(3) \\
10(10) \\
3(14)\end{array}$ & $\begin{array}{ll}3.9 & (4.8) \\
2.1 & (3.4) \\
1.4 & (2.1) \\
1.8 & (1.8) \\
1.0 & (4.5)\end{array}$ \\
\hline $\begin{array}{l}\text { Covered mattresses } \\
\text { Uncovered mattresses* }\end{array}$ & $\because$ & $\begin{array}{l}5 \\
3\end{array}$ & $\begin{array}{ll}1 & (1) \\
3 & (3)\end{array}$ & $\begin{array}{l}200 \cdot 4 \\
366 \cdot 0\end{array}$ & $17(21)$ & $\begin{array}{ll}0.5 & (0.5) \\
4.6 & (5.7)\end{array}$ \\
\hline $\begin{array}{l}\text { Soft chairs (wards)* } \\
\begin{array}{l}\text { Soft chairs (outpatient } \\
\text { departments)* }\end{array} \\
\begin{array}{l}\text { Cushions* } \\
\text { Piano stools (plush)* }\end{array}\end{array}$ & $\begin{array}{l}\cdots \\
\cdots\end{array}$ & $\begin{array}{l}5 \\
6 \\
2 \\
2\end{array}$ & $\begin{array}{ll}4 & (4) \\
5 & (5) \\
2 & (2) \\
2 & (2)\end{array}$ & $\begin{array}{r}135 \cdot 0 \\
136 \cdot 2 \\
18 \cdot 2 \\
105 \cdot 0\end{array}$ & $\begin{array}{r}60(66) \\
16(16) \\
7(7) \\
56(60)\end{array}$ & $\begin{array}{l}44.5(48.9) \\
11.7(11 \cdot 7) \\
38.5(38.5) \\
53.4(57 \cdot 1)\end{array}$ \\
\hline
\end{tabular}

*Figures include some data from the other hospitals.

$\dagger$ First figure refers to pyroglyphid mites only. Figure in parentheses represents mites of all types.

The mattresses on the hospital beds were completely enclosed in strong plastic bags. Mites were almost absent from five samples taken from beneath the plastic cover, the samples yielding between them a single specimen of Dermatophagoides pteronyssinus. Two mattresses from the general hospital and one from the skin hospital were without plastic covers and samples from these contained an average of 4.6 pyroglyphidae per $100 \mathrm{mg}$. Another mattress was found with the plastic cover split and $20.2 \mathrm{mg}$ of dust from this yielded three pyroglyphid mites.

TABLE II-Mites present on Floors of Wards in Specimens collected by VacuumCleaner. First Figure represents Pyroglyphidae only. Figure in Parentheses includes Mites of all Types

\begin{tabular}{|c|c|c|c|c|}
\hline & $\begin{array}{l}\text { General } \\
\text { Medical } \\
\text { Wards }\end{array}$ & $\underset{\text { Wards }}{\text { Geriatric }}$ & $\begin{array}{c}\text { Skin } \\
\text { Wards }\end{array}$ & $\begin{array}{c}\text { Paediatric } \\
\text { Wards }\end{array}$ \\
\hline 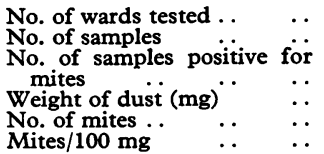 & \begin{tabular}{|cc}
9 & \\
50 & \\
23 & $(27)$ \\
$1522 \cdot 7$ & \\
59 & $(73)$ \\
3.9 & $(4 \cdot 8)$
\end{tabular} & \begin{tabular}{cc|}
22 & \\
22 & \\
7 & $(7)$ \\
$350 \cdot 0$ & $(10)$ \\
8 & $(10)$ \\
$2 \cdot 3$ & $(2 \cdot 9)$
\end{tabular} & $\begin{array}{cc}3 \\
19 \\
3 & \\
3 & (4) \\
547.7 & (4) \\
3 & (4) \\
0.5 & (0 \cdot 7)\end{array}$ & $\begin{array}{l}4 \\
11 \\
5 \\
507 \cdot 6(5) \\
8 \quad(12) \\
1 \cdot 1(1 \cdot 7)\end{array}$ \\
\hline
\end{tabular}


The highest mite numbers were found on the soft furnishings, the foam rubber cushions on the soft chairs in the wards, rest rooms, and outpatients' department, and two plush piano stools.

The results of vacuum cleaning the ward floors of the three different hospitals are compared in table II. The paediatric wards are listed separately as they housed the asthmatic children.

In the geriatric hospital fewer mites were found than on the wards of the general hospital, pyroglyphidae being present in seven out of $22(31.8 \%)$ of the vacuum-cleaner samples and in one out of $11(9.1 \%)$ of the brushed samples. The overall densities recorded were 2.3 and 0.5 pyroglyphid mites per $100 \mathrm{mg}$ of vacuum-cleaner and brushed dust respectively.

The skin hospital was visited twice. The first time six specimens of dust weighing $250.7 \mathrm{mg}$ were examined and yielded only three pyroglyphid mites, two from the direct floor samples and one from a ward vacuum-cleaner. On the next visit 13 floor samples were taken and the only mite found in all $297 \mathrm{mg}$ was a single specimen of Tarsonemous.

The distribution of mites in the sites sampled is shown in table III. In the hospital staff's clothing mites were present in six woollen overcoats, in two out of four tweed jackets, and in three sheepskin coats. One of the jackets in which no mites were found was new and the other had recently been dry-cleaned. The oldest jacket yielded 38 pyroglyphid mites and three nonpyroglyphids. The six overcoats between them provided 47 pyroglyphids and six non-pyroglyphids, and the three sheepskin coats provided 70 pyroglyphids and 10 non-pyroglyphids. A single specimen of $D$. pteronyssinus was found on a woollen cardigan. Smooth nylon raincoats and anoraks yielded fewer mites. Out of eight such coats examined three proved positive for mites, and 12 pyroglyphid and four non-pyroglyphid mites were found.

TABLE III-Numbers of Mites collected during Study in Three Hospitals and on Oxtdoor Clothing of Hospital Staff

\begin{tabular}{|c|c|c|c|c|c|}
\hline & $\begin{array}{l}\text { Ward } \\
\text { Floors }\end{array}$ & $\begin{array}{l}\text { Other } \\
\text { Floors }\end{array}$ & Beds & Chairs & Coats \\
\hline $\begin{array}{l}\text { Pyroglyphidae: } \\
\text { D. pteronyssinus } \\
\text { Euroglyphus mayne: }\end{array}$ & $\begin{array}{l}95 \\
18\end{array}$ & $\begin{array}{l}24 \\
11\end{array}$ & $\begin{array}{r}17 \\
6\end{array}$ & $\begin{array}{l}97 \\
26\end{array}$ & $\begin{array}{r}131 \\
36\end{array}$ \\
\hline 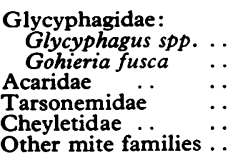 & $\begin{array}{r}12 \\
2 \\
11 \\
15 \\
1 \\
9\end{array}$ & $\begin{array}{l}9 \\
3 \\
2 \\
7 \\
2 \\
8\end{array}$ & $\begin{array}{l}1 \\
1\end{array}$ & $\begin{array}{l}1 \\
2 \\
5 \\
3\end{array}$ & $\begin{array}{r}11 \\
1 \\
6 \\
5 \\
4 \\
2\end{array}$ \\
\hline
\end{tabular}

\section{Discussion}

\section{MITES ON WARD FLOORS}

While the vacuum-cleaner was excellent for collecting the sparse dust from the open floor area the small brush was most effective in sampling the thick deposits that had built up behind water pipes and along the bases of the walls. The brushed samples were generally larger, perhaps due to the greater quantities of grit and coarse material trapped in the deposits. Even allowing for the resultant underestimation of the mite densities in the brushed samples, however, it was surprising to find such a large proportion of the mites lying relatively exposed on the open floor. Assuming that most of these mites were dead and that they were constantly being removed by regular cleaning they were probably being replaced from some source by human activity.

In a house the largest populations of pyroglyphid mites are usually found on the mattresses of beds, where densities of 257 (Cunnington, 1967) and 296 (Blythe et al., 1974) mites per $100 \mathrm{mg}$ of dust have been reported. In the hospitals, however, the plastic sealed mattresses were found to be almost devoid of mites and may therefore be discounted as the source of the mites on the ward floors. The concentrations found in the soft furnishings provided for the patients might, however, be significant.

An alternative source for the mites on the ward floors is the clothing of visitors. The jackets and overcoats of some hospital staff were examined under the assumption that they were representative of the general public, and in view of the number of mites found this source is clearly an important one.

More mites were found in the general hospital because of the higher activity in general wards, which presents problems to cleaning staff, and the large number of visitors bearing mites in their clothing.

Differences in the cleaning regimens were noticed between the hospitals. During the period of sampling vacuum-cleaning had been discontinued on the wards of the general hospital but was used in the paediatric block and in the other two hospitals, and the vacuum-cleaner is probably more effective than the mop in removing the bodies of mites. Because of the large quantities of skin scales falling on to the floors the skin hospital had a particularly rigorous and frequent cleaning programme probably accounting for the very small numbers of mites found. Vacuum-cleaners were used as part of the cleaning regimen though they were not regarded as particularly effective in removing the skin scales. The amount of food these skin scales would provide for pyroglyphid mites is largely irrelevant, as their chances of colonizing the ward floors in the face of low humidity, constant disturbance, and lack of cover would be small. The mites counted were almost all dried bodies scattered by human activity.

\section{MITES IN MATTRESSES}

The difference in the infestation between domestic and hospital mattresses was striking. Clearly, the plastic cover does prevent mite infestation either by denying the mites access, by preventing skin scales from reaching the mattress surface, or by rendering the environment unfavourable in some other way. The smooth outer surface of the plastic cover is wiped down after every patient, which also checks infestation.

Environmental humidity is an important limiting factor for pyroglyphid mites (Spieksma, 1967), which show optimum growth in culture at $80 \%$ relative humidity or higher. Hughes and Maunsell (1973) have shown that the relative humidity recorded on the surface of a mattress falls while the bed is occupied. It seems that the moisture given off by the body is in most cases insufficient to compensate for the increase in saturation deficit brought about by the rise in temperature. The occupation of a bed might therefore be presumed to have a temporarily deleterious effect on the mite population of the mattress, and Hughes and Maunsell report that the only bed which they found free from mites was occupied by one person during the day and by another at night. Hospital beds also are occupied for much of the day as well as during the night.

In conclusion, our results serve to emphasize the ubiquitous distribution of the mite allergen in the environment, even in such controlled conditions as a hospital ward. The mites on the floor have to be carried into the air and inhaled by a sensitive subject before assuming a clinical significance, and it is therefore unlikely that in the numbers found the mites constitute a serious problem for asthmatic patients. It may be worth while, however, to pay attention to those ward furnishings likely to harbour mites and to prevent as far as possible the disturbance of dust in the vicinity of asthmatic patients. The low mite count from the floors of the skin hospital in particular show what can be achieved by careful and frequent cleaning.

M.E.B. is in receipt of a grant from the Asthma Research Council, and F.A.U. received a grant from a private donor. We thank also Mr. A. Cunnington of the Pest Infestation Research Laboratory, Slough, for his advice and criticism. 


\section{References} Blythe, M. E., Williams, J. M., and Smith, J. M. (1974). Clinical Allergy,

Cunnington, A. M. (1967). Acta Allergologica, 22, 415.
Hughes, A. M., and Maunsell, K. (1973). Clinical Allergy, 3, 127.

Spieksma, F. Th. M. (1967). The House-Dust Mite. Leiden, Batteljee and Terpstra.

Voorhorst, R., Spieksma, F. Th. M., and Varekamp, H. (1969). HouseDust Atopy and the House-Dust Mite. Leiden, Stafleu's Scientific Publishing Co.

\title{
Planned Splenectomy in Treatment of Idiopathic Thrombocytopenic Purpura
}

\author{
A. I. S. MACPHERSON, JOHN RICHMOND
}

British Medical fournal, 1975, 1, 64-66

\begin{abstract}
Summary
The results of a policy of treatment in idiopathic thrombocytopenic purpura based on previous observations on the natural history of the disease and its response to corticosteroids are described. The results of splenectomy were better when the history was less than 100 days. Three patterns of response to splenectomy were observed: complete remission, symptomatic remission, and relapse. The prognosis can be determined by the level of the platelet count six weeks after splenectomy. Corticosteroid treatment for more than three weeks before splenectomy noticeably increased the incidence of complications after operation. Splenectomy can safely be performed in pregnancy. The decision to operate should be made on the maternal condition and its response to corticosteroids.
\end{abstract}

\section{Introduction}

In a previous paper (Watson-Williams et al., 1958) we examined the natural history of idiopathic thrombocytopenic purpura (I.T.P.) and the response to adrenocorticosteroids. The disorder seemed to follow two main courses. In the first there was a long history of episodic purpura, each relapse varying in severity. Spontaneous remission was common but never permanent. Treatment with corticosteroids usually initiated a short-lived remission, which, in our experience, never lasted more than two months. Patients who followed the second course had a short history (which we defined as less than 100 days from onset till the time when some treatment was begun) and a strong tendency to spontaneous and permanent remission. When treatment with corticosteroids was considered necessary permanent remission occurred in about half the patients. Rarely, patients in this short-history group had a fulminating illness with severe bleeding sufficient to require blood transfusion. The outcome was often fatal, the main cause of death being intracranial haemorrhage.

From these observations a policy of treatment was formulated with regard to splenectomy. In patients with a long history and recurrent attacks sufficiently severe to require treatment only temporary remission can be expected from corticosteroids, and the period of this remission should be used for the performance of splenectomy. Therefore, corticosteroids are given, usually

Royal Infirmary of Edinburgh, Edinburgh EH3 9YW

A. I. S. MACPHERSON, M.B., CH.M., P.R.C.S., Surgeon

JOHN RICHMOND, M.D., F.R.C.P., Reader in Medicine (Present address: Professor of Medicine, University of Sheffield, Sheffield S1 3SR). as prednisone or prednisolone $45 \mathrm{mg}-60 \mathrm{mg} /$ day, with the aim of reducing the bleeding time and the capillary fragility and possibly increasing the platelet count as a preparation for splenectomy. In patients with a short history the same treatment is given for two weeks. If remission has not occurred within that time experience has shown that it is unlikely to do so subsequently. In this event splenectomy is indicated and corticosteroids are again looked upon as a preparation for operation.

We report here the results of splenectomy in a series of 72 patients with I.T.P., all of whom had had the operation performed more than one year earlier. The series was examined, firstly, as a whole, secondly, according to whether the history was a long or a short one, and, thirdly, according to whether or not corticosteroids were used before operation.

\section{Progress after Splenectomy}

Seventy-two patients with I.T.P. were treated by splenectomy. Of these 71 were traced and reviewed periodically from one to 29 years after operation. There was complete freedom from symptoms throughout the period of review in 60 patients and recurrence in $11(15 \%)$. Recurrence took the form of epistaxis in four patients, melaena in three (one of whom had previously had a partial gastrectomy for gastric ulcer), purpura in five, menorrhagia in three, and a cerebrovascular accident in two. The time of the recurrent symptoms ranged from immediately after operation to 12 years later. In 10 patients the platelet count was known to be subnormal at the time symptoms recurred. It had been normal for two years after splenectomy in the 11th patient but had not been checked close to the time of her relapse. There were two deaths attributable to the bleeding abnormality, both patients dying with symptoms suggestive of intracranial haemorrhage. The first (case 1) was a woman aged 55 with a short history of purpura who died 19 days after operation from intracerebral haemorrhage, never having shown any response in symptoms or platelet count to splenectomy. The second (case 2) was a girl aged 14 who died eight years after splenectomy. Her platelet count had been consistently normal but shortly before death, which occurred at home, purpura recurred. Necropsy was not performed and death was certified as due to intracranial haemorrhage, but the possibility of meningitis cannot be excluded.

It was possible to distinguish three patterns of behaviour after splenectomy for I.T.P. (fig. 1). In the first group there was complete relief of symptoms. The bleeding time returned at once to normal, and the platelet count rose sharply in the first two weeks after operation to three or four times the normal level and then came down to and remained above $150000 / \mathrm{mm}^{3}$. 